\title{
Rapid Methodologies for Assessing Pseudomonas syringae pv. actinidiae Colonization and Effector-Mediated Hypersensitive Response in Kiwifruit
}

\author{
Jay Jayaraman, ${ }^{1,2}$ Abhishek Chatterjee, ${ }^{1}$ Shannon Hunter, ${ }^{1}$ Ronan Chen, ${ }^{3}$ Erin A. Stroud, ${ }^{1,4}$ Hassan Saei, ${ }^{3}$ \\ Stephen Hoyte, ${ }^{5}$ Simon Deroles, ${ }^{3}$ Jibran Tahir, ${ }^{1}$ Matthew D. Templeton, ${ }^{1,2,4, \dagger}$ and Cyril Brendolise ${ }^{1, \dagger}$ \\ ${ }^{1}$ The New Zealand Institute for Plant and Food Research Limited, Auckland, New Zealand \\ ${ }^{2}$ Bio-Protection Research Centre, Lincoln, New Zealand \\ ${ }^{3}$ The New Zealand Institute for Plant and Food Research Limited, Palmerston North, New Zealand \\ ${ }^{4}$ School of Biological Sciences, University of Auckland, Auckland, New Zealand \\ ${ }^{5}$ The New Zealand Institute for Plant and Food Research Limited, Ruakura Research Centre, Hamilton, New Zealand
}

Accepted 8 April 2021.

\begin{abstract}
The infection of Pseudomonas syringae pv. actinidiae in kiwifruit is currently assessed by numerous methodologies, each with their own limitations. Most studies are based on either a laborious method of growth quantification of the pathogen or qualitative assessments by visual scoring following stem or cutting inoculation. Additionally, when assessing for resistance against specific pathogen effectors, confounding interactions between multiple genes in the pathogen can make mapping resistance phenotypes nearly impossible. Here, we present robust alternative methods to quantify pathogen load based on rapid bacterial DNA quantification by PCR, the use of Pseudomonas fluorescens, and a transient reporter eclipse assay for assessing resistance conferred by isolated bacterial avirulence genes. These assays compare well with bacterial plate counts to assess bacterial colonization as a result of plant resistance activation. The DNA-based quantification, when coupled with the $\boldsymbol{P}$. fluorescens and reporter eclipse assays to independently identify bacterial avirulence genes, is rapid, highly reproducible, and scalable for high-throughput screens of multiple cultivars or genotypes. Application of these methodologies will allow rapid and high-throughput identification of resistant cultivars and the bacterial avirulence genes they recognize, facilitating resistance gene discovery for plant breeding programs.
\end{abstract}

Keywords: Actinidia arguta, electrolyte leakage, PDQeX, qPCR, resistance

${ }^{\dagger}$ Corresponding authors: M. Templeton; Matt.Templeton@plantandfood.co.nz and C. Brendolise; Cyril.Brendolise@plantandfood.co.nz

Funding: This work was funded (including a post-doctoral fellowship to J. Jayaraman) by the Bio-Protection Research Centre (Tertiary Education Commission), New Zealand.

*The $\boldsymbol{e}$-Xtra logo stands for "electronic extra" and indicates there is supplementary material published online.

The author(s) declare no conflict of interest.

(c) (1) () $\odot$ Copyright $(\odot 2021$ The Author(s). This is an open access article distributed under the CC BY-NC-ND 4.0 International license.
The plant immune system is central to plant survival when constant pathogen and pest attack threatens host survival and crop productivity. The prevailing concept for how the immune system in plants is structured is a bipartite innate immune system, consisting of a plant cell membrane-associated pattern-triggered immunity (PTI) and an intracellular effector-triggered immunity (ETI). PTI is activated by conserved microbial particles present in the apoplastic space, whereas ETI is typically activated by pathogen effector proteins sensed by intracellular receptors that subsequently add to the PTI response (Cook et al. 2015; Jones et al. 2016; Ngou et al. 2021; Yuan et al. 2021). Bacterial pathogens secrete around 30 effectors into plant cells to facilitate infection, with the best-characterized mechanism by which this occurs utilizing a type III secretion system (T3SS). If an effector is recognized by the plant surveillance system, which is comprised of a repertoire of resistance $(R)$ genes, ETI is triggered, inducing an avirulence response and is termed an avirulence effector. ETI is often associated with a robust programmed cell death response and production of reactive oxygen species (ROS) that collectively result in a phenotype known as the hypersensitive response (HR) (Zurbriggen et al. 2010). Identification of the genetic determinants that trigger ETI in a resistant plant and introgressing them into commercially attractive susceptible plants is the ultimate goal of a plant disease-resistance breeding program. This requires a methodology for robustly assessing disease establishment and the resistance mechanisms preventing this in plant hosts.

For Pseudomonas syringae pv. actinidiae, the causal pathogen of kiwifruit bacterial canker, several different assays have been reported to assess disease in planta (Hoyte et al. 2015; McCann et al. 2013; Wang et al. 2019). However, it is difficult to distinguish resistance (typically robust gene-for-gene responses) from tolerance (typically a quantitative trait) or susceptibility due to a reliance on symptomology, laborious plant tissue manipulation, a time-consuming phenotyping process, variability associated with minor alterations in environmental conditions, or a combination of these, using these reported assays (Tahir et al. 2019).

The Arabidopsis thaliana-Pseudomonas syringae pathosystem has been widely utilized as a model for plant-bacterial interactions. The $P$. syringae pv. tomato DC3000 strain has been used for visual evaluation of disease symptoms, in vivo pathogen counting methods, or fluorescence tracking and quantification, as well as highthroughput quantitative PCR (qPCR)-based methodologies with high consistency between experiments (Brouwer et al. 2003; Fan et al. 2008; Ross and Somssich 2016; Whalen et al. 1991). 
The qPCR-based method utilizes primers specific to the pathogen and a normalizing reference gene (typically of plant origin) to quantify the amount of pathogen DNA compared with plant DNA in an extracted sample (Brouwer et al. 2003; Ross and Somssich 2016). Unlike visual symptomology and pathogen tracking, in vivo-pathogen counting is accurate and is able to distinguish even small changes in colonization by the pathogen, but it is labor intensive and time consuming. In contrast, qPCR-based methodologies are accurate, rapid, and have the advantage of long-term storage of material following harvest of infected plant tissue not possible for in vivo-pathogen counting, allowing comparisons of large sample sets (Ross and Somssich 2016). qPCRbased methodologies for $P$. syringae pv. actinidiae have recently been developed (Gallelli et al. 2014), with modifications for normalization being added to improve quantification between different cultivars (Barrett-Manako et al. 2021).

While the aforementioned assays developed for the Arabidopsis$P$. syringae pathosystem are translatable to other crop plant systems and their cognate pathogens, the complexity of numerous $R$ genes in a plant recognizing multiple genes in the pathogen can confound $R$-gene discovery. Thus, the first step to identifying a plant $R$ gene to be utilized in a breeding program is often isolating the avirulence effector, to avoid confusing interplay between that effector and others that may be present in the pathogen as well as to overcome redundancy issues (Thomas et al. 2009; Vleeshouwers and Oliver 2014). To be able to discover and exploit avirulence effectors as a tool in breeding, a rapid and robust screening technology must be developed and deployed (Dangl et al. 2013).

In this respect, a number of transient assay systems for isolated effector expression have been adapted to a variety of model and crop plants to streamline $R$ gene discovery. Transient expression of genes using Agrobacterium tumefaciens or viruses have been the predominant way to express putative avirulence effectors in resistant plants to rapidly screen for resistance (Du et al. 2014; Rietman et al. 2012). The requirement of the plant to trigger an $\mathrm{HR}$ is critical to this methodology but may not always be produced in response to an avirulence effector (Gassmann 2005; Jayaraman et al. 2017; Laflamme et al. 2020). In addition, transient expression screens are achieved through syringe infiltration of an Agrobacterium tumefaciens strain, which may be difficult for some plant species and needs to be optimized for each species (Hayta et al. 2019; Jelly et al. 2014; Wroblewski et al. 2005; Zhao et al. 2019). Alternatively, biolistic bombardment of plant tissue using coexpression of a reporter gene with a putative avirulence gene has been used to check for HR reducing expression of the reporter gene, a reporter eclipse assay (Gopalan et al. 1996; Jia et al. 2000; Mindrinos et al. 1994). Reporter eclipse assays are currently underutilized in analysis of resistance because of technical issues regarding reproducibility and fine-tuning assay parameters but remain relevant, particularly for multiple-construct transformations (Agrawal et al. 2005).

Previously, $P$. syringae pv. actinidiae infection in tissue culture-grown plantlets was quantified for pathogen growth in planta following a flooding inoculation method (mimicking natural infection) as well as stab inoculations (McAtee et al. 2018; McCann et al. 2013). These assays, based on axenically grown plantlets in tissue culture, are reproducible but are nevertheless laborious and time consuming. Recently, a robust methodology for qPCR-mediated quantification of $P$. syringae pv. actinidiae infection was described for kiwifruit (Barrett-Manako et al. 2021; Gallelli et al. 2014). Sampling and DNA extraction issues were noted as limitations. Here, we build on previous work to report several optimized higher-throughput assays for pathogen quantification and avirulence determination in tissue culture-grown kiwifruit plantlets, including in comparison with classical plate assays. We develop two novel approaches that can be applied to different cultivars of kiwifruit and can be deployed for accurate and rapid determination of avirulence presence in the pathogen critical to resistance breeding programs.

\section{RESULTS}

Kiwifruit cultivars demonstrate wide variation in their response to $P$. syringae pv. actinidiae biovar 3 (Psa3).

To assess the variability in the response of different commercially grown kiwifruit cultivars, four selected cultivars grown as plantlets were flood-inoculated with Psa3. Photographs taken at 50 days postinfection show that they varied phenotypically from highly susceptible (Actinidia chinensis var. chinensis Hort16A), moderately susceptible (A. chinensis var. chinensis Zesy002), tolerant (A. chinensis var. deliciosa Hayward), and resistant ( $A$. arguta AA07_03) (Fig. 1A). The disease symptomology of these tissue culture-grown plantlets reflected closely field- and glasshouse-grown plants for these cultivars (Supplementary Fig. S1) (Hoyte et al. 2015). To assess whether the symptoms reflected the level of colonization by Psa3 in the host, in-planta growth assays were conducted at 6 and 12 days postinfection (Fig. 1B; Supplementary Fig. S2). Surprisingly, despite large variations in symptomology, even early during the infection process, no difference in in-planta growth was noted for Hort16A compared with Zesy002 and only a small but significant difference was noted for Hayward. In contrast, AA07_03 plants showed significantly reduced in-planta growth by $P$ sa3. This was also in line with previously reported resistance in $A$. arguta and tolerance seen for $A$. chinensis var. deliciosa (Donati et al. 2020; Nardozza et al. 2015; Wang et al. 2019). These findings indicated that, while symptomology was ideal for studying differences in tolerance (measured through production of deleterious symptoms on the plant), it was neither the most appropriate nor the quickest assay method for assessing genetic resistance in kiwifruit (a lack of pathogen colonization as well as a lack of disease symptoms). Notably, though, this traditional approach to assessing resistance was achieved in 2 weeks, with significant limitations on the number of plant genotypes (6 to 12) able to be assessed per run because of labor requirements and time restrictions (Table 1).

To increase the throughput of assessing resistance in infected plants, the quantification of Psa3 colonization of the host tissues was also undertaken, using a novel DNA extraction method (PDQeX), which simplified and streamlined extraction (Stanton et al. 2019), coupled to previously reported qPCR-based detection (Barrett-Manako et al. 2021). This coupled approach of PDQeXqPCR for plants sampled at 7 days postinoculation (dpi) reproduced the resistance in AA07_03 seen by traditional growth assays (Fig. 1C). This infection-sampling PDQeX-qPCR approach reduced assessment times to half that of the traditional plating approach, with the added benefit of allowing around 24 individual plant genotypes to be assessed per run (Table 1) and is an improvement on the previous throughput possible (Barrett-Manako et al. 2021).

To further improve throughput of screening, an HR assay measuring electrolyte leakage (conductivity) was developed for Psa3, to test for cell death in response to the pathogen. Unfortunately, kiwifruit is not amenable to syringe-based infiltration and required vacuum-infiltration to achieve consistent levels of leaf infection. The use of vacuum-infiltration and measurement of electrolyte leakage would speed up resistance assessment times to approximately 2 days postinfection (Table 1). Using vacuum-infiltration of Psa3 and its T3SS nonexpressing mutant $(\Delta h r c C)$ into the four kiwifruit cultivars resulted in some early ( 6 to $24 \mathrm{~h}$ ) increase in electrolyte leakage indicating HR (Fig. 1D). However, while consistent late increases ( 24 to $48 \mathrm{~h}$ ) for wild-type Psa3 suggested normal function for its T3SS, vis-à-vis electrolyte leakage associated with effector-mediated virulence functions, it also indicated that a clear HR-associated leakage was less obvious (with a high 
rate of leakage indicating HR, particularly comparing the most susceptible and most resistant genotypes, Hort16A and AA07_03). The small early electrolyte leakage was consistent irrespective of the level of Psa3 inoculum used for this assay $\left(10^{7}\right.$ to $\left.10^{9} \mathrm{CFU} / \mathrm{ml}\right)$. Indeed, deployment of traditional ROS detection assays to detect the secondary oxidative burst during HR also did not indicate a clear difference between the most susceptible (Hort16A) and most resistant (AA07_03) plant genotypes (Supplementary Fig. S3), despite testing showing that AA07_03 mounted a significant defense-gene expression response against Psa3, unlike Hort16A (Supplementary Fig. S4). The reason, at this stage, for the lack of a clear HR response was unclear,
A

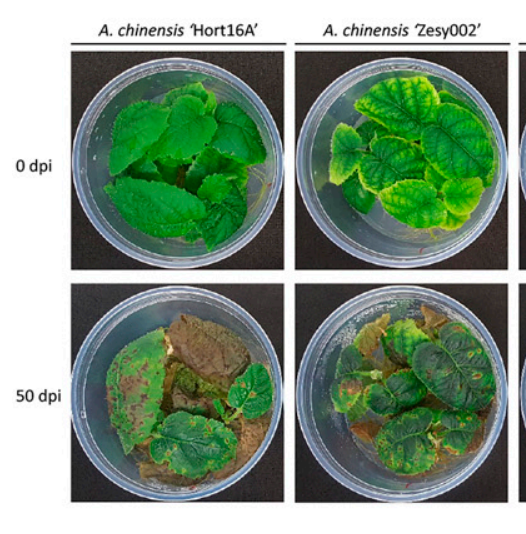

B

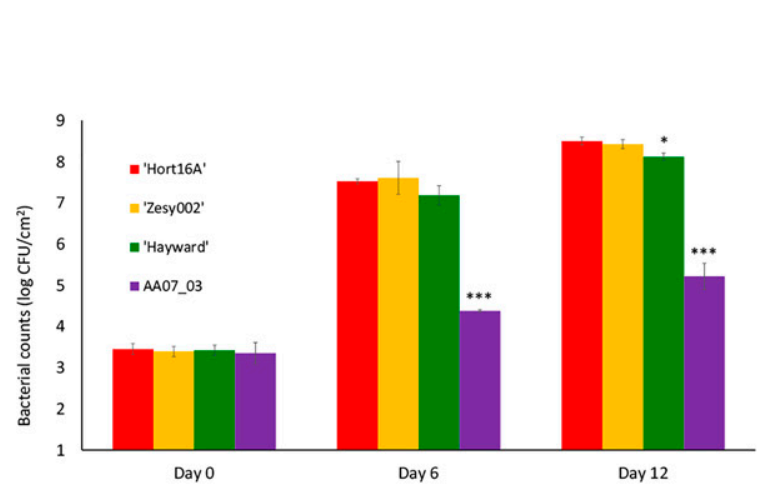

C

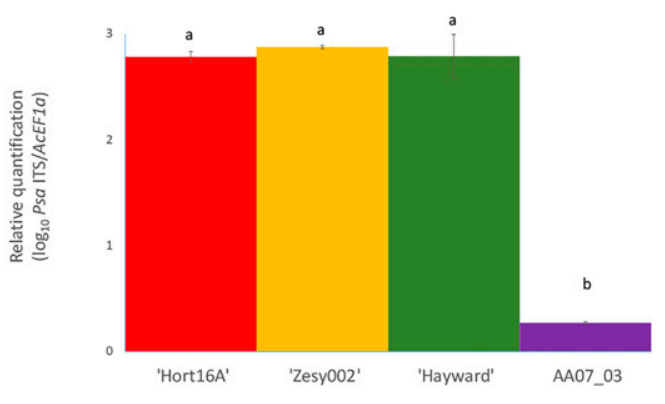

D

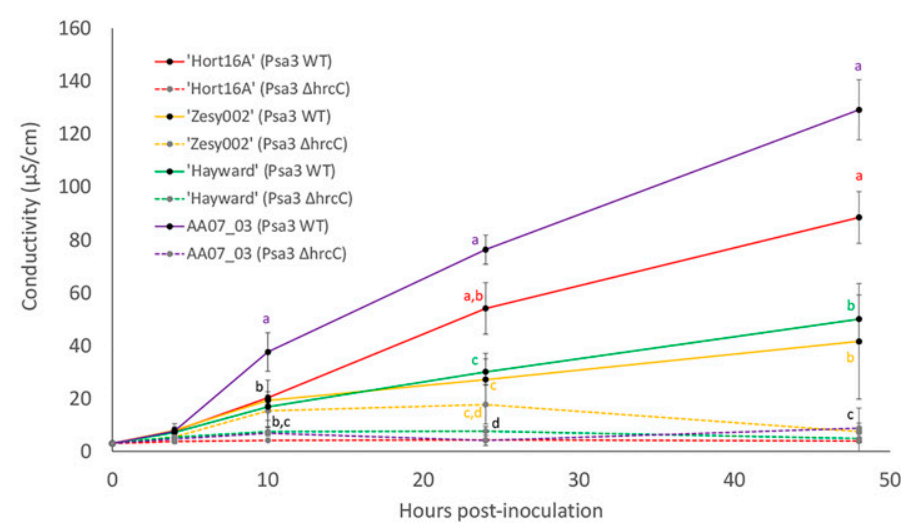

Fig. 1. PDQeX-quantitative PCR (qPCR) is better than symptomology or electrolyte leakage for quantifying Pseudomonas syringae pv. actinidiae ICMP 18884 (Psa3) infection in commonly grown kiwifruit cultivars. A, Symptom development in Actinidia chinensis var. chinensis cultivar Hort16A, A. chinensis var. chinensis Zesy002, A. chinensis var. deliciosa Hayward, and A. arguta AA07_03 plantlets at 50 days postinoculation (dpi) with Psa3. Psa3 was floodinoculated at approximately $10^{6} \mathrm{CFU} / \mathrm{ml}$ into plantlets and photographs were taken of a single representative pottle displaying typical disease lesion symptoms, if present. B, Psa 3 growth in multiple kiwifruit cultivars determined by classical in-planta growth quantification by serial dilution and plating. Psa 3 was flood-inoculated as described in A, and bacterial growth was determined 0, 6, and 12 dpi. Error bars represent standard error of the mean from four pseudobiological replicates. Asterisks indicate results of a two-tailed Student's $t$ test between the selected treatment and susceptible Hort6A; one asterisk $(*)$ indicates $P<0.05$ and three $(* * *) P<0.001$. The experiment was conducted three times with similar results. $\mathbf{C}, P s a 3$ growth in multiple kiwifruit cultivars determined by PDQeX-qPCR. Psa3 was flood-inoculated as described in A, and bacterial presence in leaf samples was quantified by qPCR for the Psa3 intergenic transcribed spacer region normalized to AcEF1 $\alpha$ for $7 \mathrm{dpi}$. Error bars represent standard error of the mean from four pseudobiological replicates. Letters indicate results of a one-way analysis of variance (ANOVA) and Tukey's honest significant difference (HSD) post hoc test $(P<0.01)$, shared letters indicate no significant difference. The experiment was conducted three times with similar results. D, Measurement of hypersensitive response (HR) by electrolyte leakage. Leaf discs from plantlets shown in A were vacuum-infiltrated with Psa3 inoculum at approximately $10^{8} \mathrm{CFU} / \mathrm{ml}$, and electrical conductivity due to HR-associated electrolyte leakage was measured at selected timepoints over $48 \mathrm{~h}$. The curves are generated from the combination of three independent runs of this experiment. Error bars represent the standard errors of the means calculated from the three experimental runs, each with five pseudobiological replicates. Letters indicate results of a one-way ANOVA and a Tukey's HSD post hoc test for each timepoint, with shared letters indicating no statistical significance $(P<0.01)$.

Table 1. Comparison of assay parameters for screening resistance in kiwifruit plants

\begin{tabular}{|c|c|c|c|}
\hline Assay & Assessment & Samples per run & Time to completion (days) \\
\hline In planta growth and plating & Bacterial colonization of host & 6 to 12 & 14 \\
\hline PDQeX-qPCR & Bacterial colonization of host & 6 to 24 & 7 \\
\hline Electrolyte leakage (Pseudomonas fluorescens) & Hypersensitive response & 24 to 48 & 2 \\
\hline Reporter eclipse (biolistic) & Hypersensitive response & 6 to 12 & 2 \\
\hline
\end{tabular}


including whether Psa3 was capable of suppressing the HR while still triggering plant immunity.

\section{Psa3-delivery of avirulence effectors triggers resistance in Hort16A but not HR.}

To assess whether kiwifruit was capable of producing a resistance response typically seen in model plants (Arabidopsis thaliana and Nicotiana benthamiana), Psa3 was first transformed with plasmid vectors carrying known avirulence effectors recognized in these model plants (Bisgrove et al. 1994; Century et al. 1995; Kunkel et al. 1993; van Dijk et al. 2002). The effectors chosen were avrRpt2 from $P$. syringae pv. tomato T1 (representing $P$. syringae phylogroup 1), hopAl from $P$. syringae pv. syringae 61 (representing $P$. syringae phylogroup 2), avrPphB from $P$. syringae pv. phaseolicola $1448 \mathrm{~A}$ (representing $P$. syringae phylogroup 3), and avrRpml from $P$. syringae pv. maculicola M2 (since it is an ortholog of an effector present in Psa3). The transformed Psa3 strains were then tested in susceptible Hort16A plants for reduced in-planta growth and lack of disease symptom production as measures of resistance in response to the introduced effectors.

Infection of Hort16A plants resulted in in-planta growth and associated plant disease symptoms identical to wild-type Psa3 for both Psa3 + avrPphB and Psa3 + avrRpml (Fig. 2A and B; Supplementary Fig. S5). However, for both Psa3 + avrRpt2 and Psa3 + hopA1, a strong reduction in in-planta growth and symptomology suggested both of these effectors were recognized by Hort16A plants. The in-planta growth and symptomology testing results were also confirmed by PDQeX-qPCR testing, indicating that both AvrRpt2 and HopA1 are avirulence effectors recognized by Hort16A (Fig. 2C). Notably, these effector-carrying strains could not trigger early HR-associated electrolyte leakage despite the very strong reductions in virulence detected through the traditional in-planta growth and disease symptomology assays, similar to Psa3 in AA07_03 (Supplementary Fig. S6).

\section{Novel assays discover avirulence effectors recognized by Hort16A and AA07_03.}

To assess whether the lack of a clear HR response was due to Psa3-mediated interference or whether kiwifruit plants were atypical in their ability to trigger an HR, P. fluorescens Pf0-1 with and without a T3SS were transformed with the plasmids bearing these four effectors and were tested for electrolyte leakage. Interestingly, when delivered by P. fluorescens (T3S), both AvrRpt 2 and HopA1 triggered large increases in electrolyte leakage, in contrast to delivery by $P$. fluorescens (wild type [WT]) for these effectors or AvrPphB (Fig. 3A). Surprisingly, P. fluorescens (T3S) + avrRpm1 also triggered strong electrolyte leakage, which was, in fact, stronger than the responses seen for AvrRpt2 and HopA1. This suggested that AvrRpt2 and HopA1 are both strong avirulence effectors that trigger immunity but not HR when delivered by Psa3. In contrast, AvrRpm1 failed to trigger both immunity and HR when delivered by Psa3 but triggered a strong HR when delivered individually by $P$. fluorescens. This further validated the use of $P$. fluorescens as a tool for rapidly screening for resistance in kiwifruit, allowing for testing a larger number of plants (12 to $24)$ but in a significantly reduced timeframe (2 days) (Table 1$)$.

To confirm the results of the isolated effector delivery system, a transient expression system via biolistic bombardment was developed in parallel for kiwifruit that utilized a coexpression of an effector of interest together with a reporter gene for detecting HR. This reporter eclipse system measured the uidA ( $\beta$-glucuronidase [GUS]) reporter gene activity in leaf tissues cobombarded with the putative avirulence effector, and the level of the HR inversely correlated to the level of the GUS activity. Recent findings demonstrated that PTI activation was required to prime for ETI and associated HR (Ngou et al. 2021; Yuan et al. 2021).
Expression of some nucleotide-binding leucine-rich receptor (NLR) genes, such as $N R G 1$, is induced upon activation of PTI (Brendolise et al. 2018), thus, a pretreatment of the plant tissue with an Agrobacterium sp. was included in our reporter eclipse system to induce PTI. Using this primed reporter eclipse assay, coexpression of AvrRpt2 and HopA1 in Hort16A leaves significantly reduced expression of the GUS reporter compared with that when coexpressed with empty vector or AvrPphB (Fig. 3B). Interestingly, coexpression with AvrRpm1 also resulted in a significant reduction of reporter expression, suggesting that it was triggering HR in Hort16A leaves.

To examine if these three effectors are also recognized in AA07_03, P. fluorescens (T3S) and P. fluorescens (WT), delivery of the four effectors was also tested for electrolyte leakage. In this Psa3-resistant host, only AvrRpt2 and HopA1 resulted in an HR response with electrolyte leakage and AvrRpm1 failed to produce a strong HR-associated phenotype (Fig. 4A). Using the primed reporter eclipse assay to confirm this result produced identical findings, suggesting that unlike Hort16A, AA07_03 plants only recognized HopA1 and AvrRpt2 expression (Fig. 4B). Taken together, this suggested that Hort16A and AA07_03 share recognition of AvrRpt 2 and HopA1 but differ in their recognition of AvrRpm1.

\section{DISCUSSION}

Assessing disease resistance in kiwifruit during infection by Psa3 is currently undertaken symptomologically (which can be unreliable) or through quantification of bacterial colonization by traditional plate-counting methods (accurate and reliable but low-throughput). This is particularly cumbersome because of the need for immediate processing of harvested samples, making the entire process time-consuming and laborious. Furthermore, different cultivars may have distinct leaf morphologies, thus the available colonization capacity of the plant may naturally vary. This latter issue would require an internal normalization process to facilitate adjustment for variation between cultivars but is unavailable for classical growth assays.

DNA-based detection as an alternative to classical infection quantification has been deployed for plant-pathogen studies in other pathosystems but has not yet been deployed in the $P$. syringae pv. actinidiae-kiwifruit system until recently (Abdullah et al. 2018; Barrett-Manako et al. 2021; Brouwer et al. 2003; Gallelli et al. 2014; Narusaka et al. 2009; Ross and Somssich 2016; Weßling and Panstruga 2012). The use of nucleic acid extraction tools for DNA-based detection has typically been the rate-limiting step for this approach. However, the use of the high-quality, rapid DNA extraction methodology (PDQeX) in our work has significantly accelerated this component and is validated here for relative quantification studies for the first time (Stanton et al. 2019). Furthermore, because of the higher sensitivity of the qPCR assay (detection accomplished over twofold increments compared with 10 -fold increments with classical plating assays), a shorter period of assessment ( $7 \mathrm{dpi}$ ) can be utilized, further speeding up the process of assessing pathogen colonization of the plant host.

The use of transient assays and isolated effector delivery assays in model plants for Psa3 has been reported recently but has not, until now, been deployed consistently for kiwifruit (Brendolise et al. 2017; Choi et al. 2017; Jayaraman et al. 2017). Taken together, a number of the assays demonstrated herein are both efficacious and high-throughput for quantifying both the pathogen growth (PDQeX-qPCR) and plant response to the presence of an HR-triggering avirulence effector (electrolyte leakage and reporter eclipse). The transient biolistic approach serves as a stand-in for classical Agrobacterium-medium transient assays (agroinfiltration) that typically examine HR and HR-like responses in plants, which are recalcitrant to agroinfiltration-type syringe-infiltration 
experiments (Lacroix and Citovsky 2020; Ueki et al. 2013). The biolistic approach also allows organelle targeting, does not require the discovery of a coevolved Agrobacterium strain, and is often significantly more rapid in application than other transient expression methods (Lacroix and Citovsky 2020). However, the biolistics approach has only moderate throughput, as each sample requires significant handling, and thus, it is not an ideal first tool for screening large numbers of plants (Table 1) but instead is useful as

\section{A}

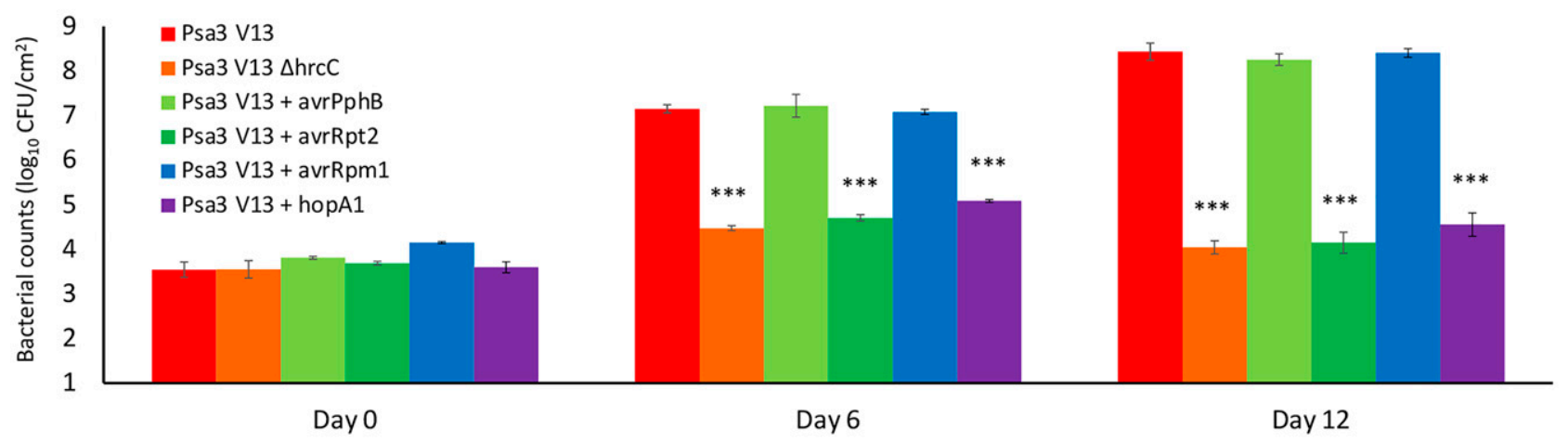

B

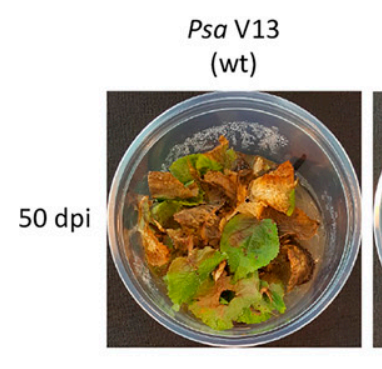

Psa V13

$(\triangle h r c C)$

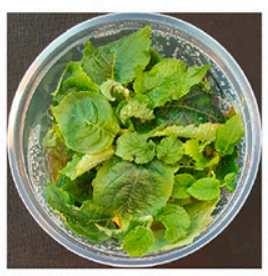

Psa V13

(+avrPphB)

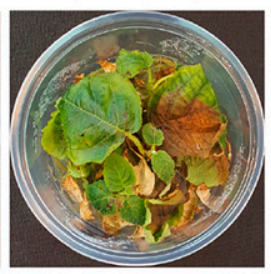

Psa V13

(+avrRpt2)

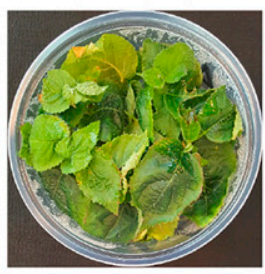

Psa V13

(+avrRpm1)

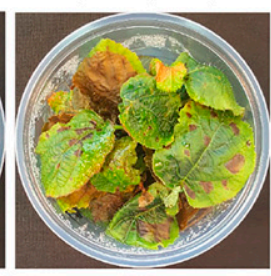

Psa V13

(+hopA1)

C

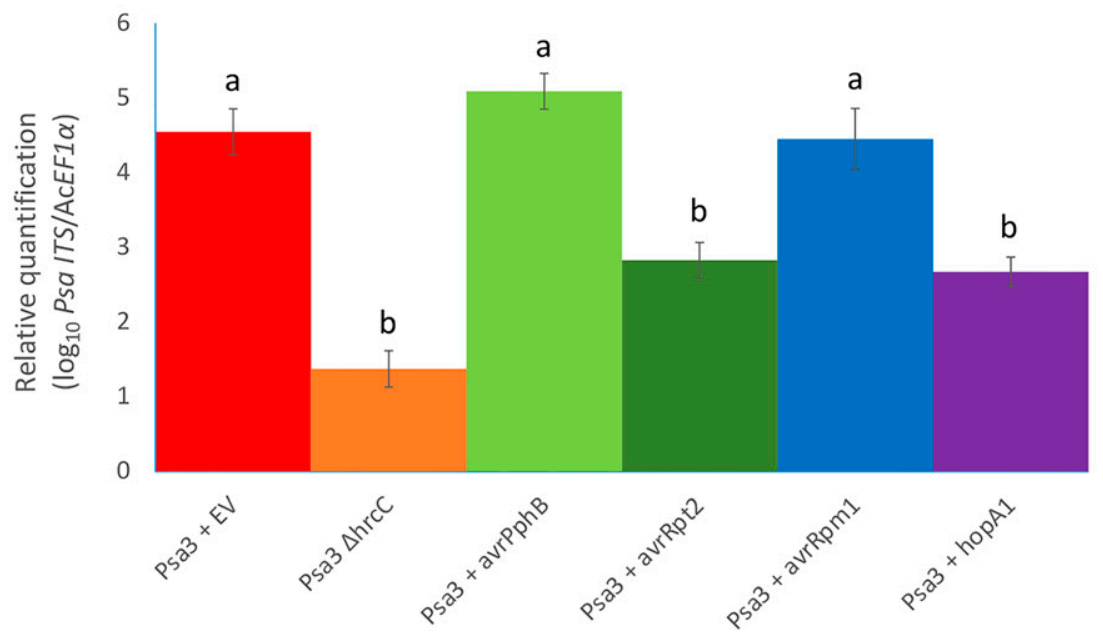

Fig. 2. Actinidia chinensis var. chinensis Hort $16 \mathrm{~A}$ recognizes effectors AvrRpt $2_{P t o \mathrm{~T} 1}$ and $\mathrm{HopA} 1_{P s y 61}$ when delivered by Pseudomonas syringae pv. actinidiae ICMP 18884 (Psa3). A, Growth of Psa3 variants in Hort16A plantlets was determined by in-planta growth quantification by serial dilution and plating.

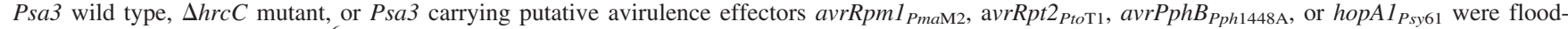
inoculated, at approximately $10^{6} \mathrm{CFU} / \mathrm{ml}$, into plantlets and bacterial growth was determined 0,6 , and 12 days postinoculation (dpi). Error bars represent standard error of the mean from four pseudobiological replicates. Asterisks indicate results of a two-tailed Student's $t$ test between the selected treatment wild type; three asterisks $(* * *)$ indicate $P<0.001$. The experiment was conducted three times with similar results. B, Symptom development in Hort 16A plantlets at $50 \mathrm{dpi}$ after inoculation with strains shown in A. Photographs were taken of a single representative pottle displaying typical disease lesion symptoms, if present. C, Psa3 growth in multiple kiwifruit cultivars determined by PDQeX-quantitative PCR (qPCR). Psa3 strains were flood-inoculated as described in $\mathrm{A}$, and bacterial presence in leaf samples was quantified by qPCR for the Psa3 intergenic transcribed spacer region normalized to AcEF $1 \alpha$ at $7 \mathrm{dpi}$. Error bars represent standard error of the mean from four pseudobiological replicates. Letters indicate results of a one-way analysis of variance and Tukey's honest significant difference post hoc test $(P<0.01)$, shared letters indicate no significant difference. The experiment was conducted three times with similar results. 
a heterologous system free of HR-like elicitation occasionally associated with recognition of the type III secretion system itself (Clarke et al. 2014, 2010).

In contrast, the HR-associated electrolyte leakage assays are eminently suitable for high-throughput screens of multiple cultivars and $F_{1} / F_{2}$ mapping populations from crosses. However, to be useful, these screens need to be verified via a pathogen infection assay (e.g., PDQeX-qPCR) for the deconvolution of HR from the effect of other effectors that seek to block HR and side effects of other virulence-promoting activities (Vleeshouwers and Oliver 2014). Numerous $P$. syringae effectors have been identified that are capable of suppressing the HR triggered by an avirulence

A

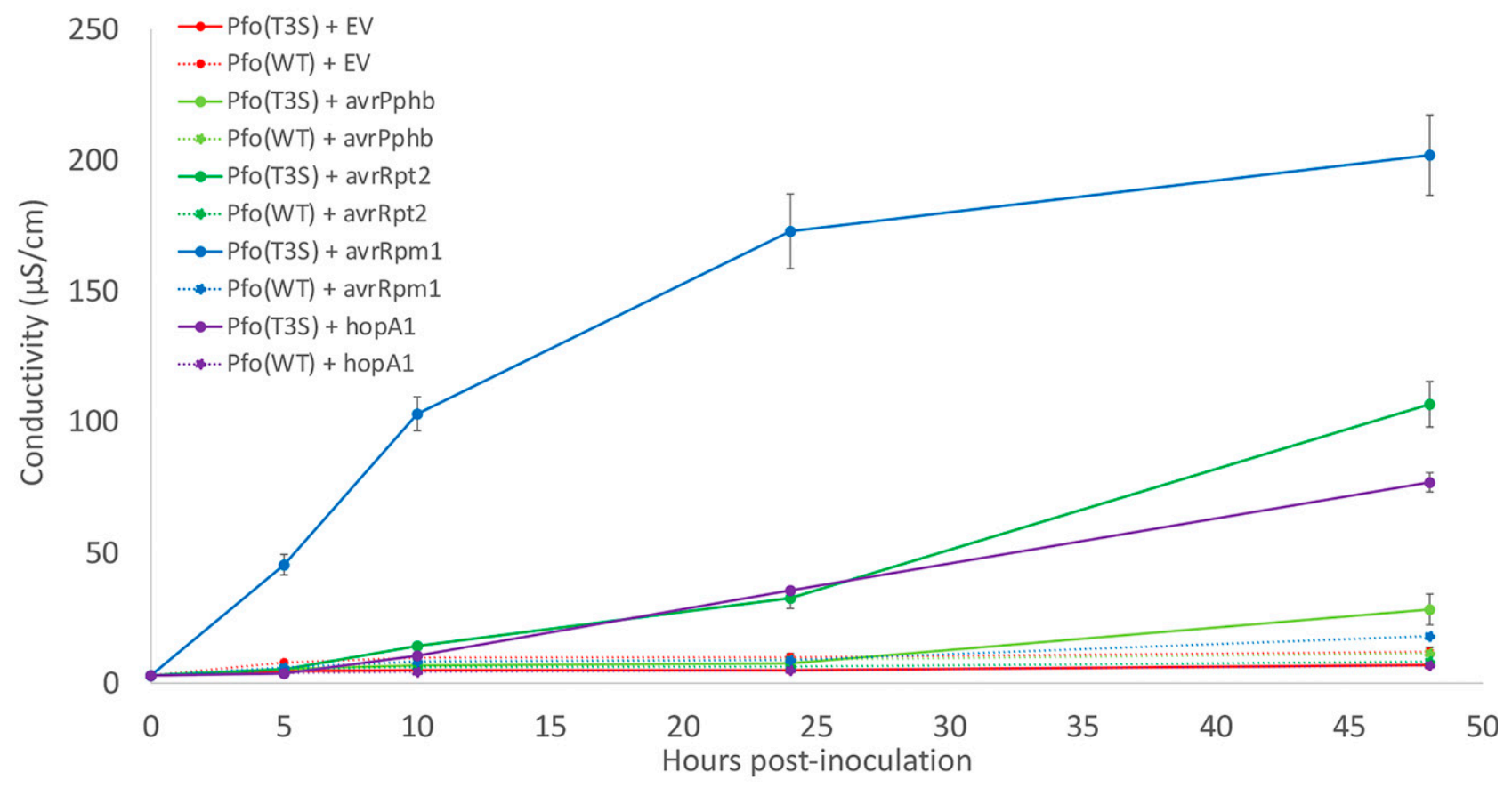

B

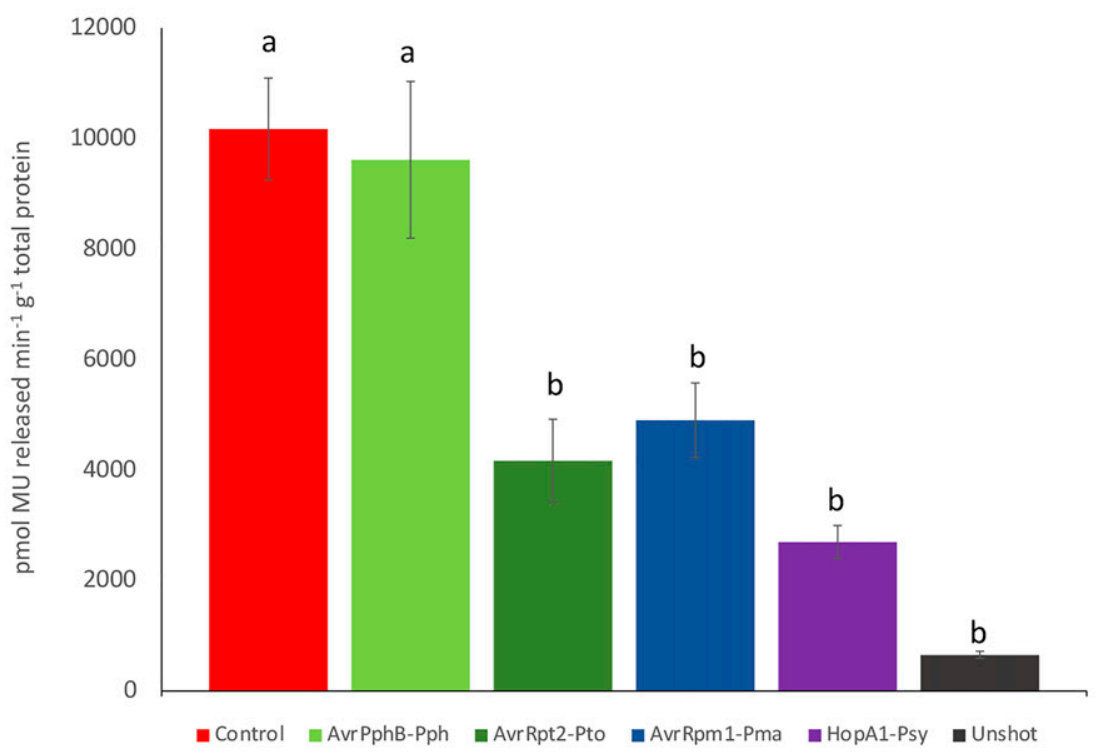

Fig. 3. Actinidia chinensis var. chinensis cultivar Hort 16 recognizes effectors AvrRpt $2_{P t o \mathrm{~T} 1}, \mathrm{HopA} 1_{P s y 61}$, and AvrRpm $1_{P m a \mathrm{M} 2}$ when delivered in isolation or during transient expression. A, Measurement of hypersensitive response (HR) by electrolyte leakage. Leaf discs from Hort16A plantlets were vacuuminfiltrated with $P$. fluorescens Pf0-1 wild type (WT) or type III secretion system carrying mutant (T3S) carrying empty vector (EV) or putative avirulence effector genes $a v r R p m 1_{P m a \mathrm{M} 2}$, avrRpt $2_{P t o \mathrm{~T} 1}, a v r P p h B_{P p h 1448 \mathrm{~A}}$, or $h o p A 1_{P s y 61}$ inoculum at approximately $10^{8} \mathrm{CFU} / \mathrm{ml}$, and electrical conductivity due to HR-associated electrolyte leakage was measured at selected timepoints over $48 \mathrm{~h}$. Error bars represent the standard errors of the means calculated from five biological replicates. B, Putative avirulence effectors, described in A, cloned on binary vector constructs or corresponding empty vector (EV) were coexpressed with a $\beta$-glucuronidase (GUS) reporter construct, using biolistic bombardment and priming in Hort16A plantlets. The GUS activity was measured $48 \mathrm{~h}$ after DNA bombardment. Error bars represent the standard errors of the means for three independent biological replicates with six technical replicates each $(n=18)$. Letters indicate results of a one-way analysis of variance and Tukey's honest significant difference post hoc test $(P<0.01)$, shared letters indicate no significant difference. 
gene (Choi et al. 2017; Guo et al. 2009). This is clearly the case for HR in kiwifruit, in particular, because Psa3 delivery of in-planta bacterial growth-restricting effectors (AvrRpt2 and HopA1) did not lead to detectable HR (Supplementary Fig. S5).

The results obtained with AvrRpm1 in this study typify the need for deconvoluting HR-inducing effectors from HR-suppressing effectors, since Hort16A plants were able to recognize and trigger a strong electrolyte leakage response to this effector when delivered by $P$. fluorescens and reporter eclipse during transient expression (Fig. 3). However, pathogen growth did not show an avirulenceassociated pathogen growth restriction (Fig. 2). This was not the case for AvrRpt2 or HopA1, both of which had strong pathogen growth suppression and HR. The likelihood of an AvrRpm1associated artifact is reduced, since the same $P$. fluorescens (T3S) strain delivery of AvrRpm1 failed to trigger an HR response in AA07_03, suggesting an authentic host genotype-specific

\section{A}

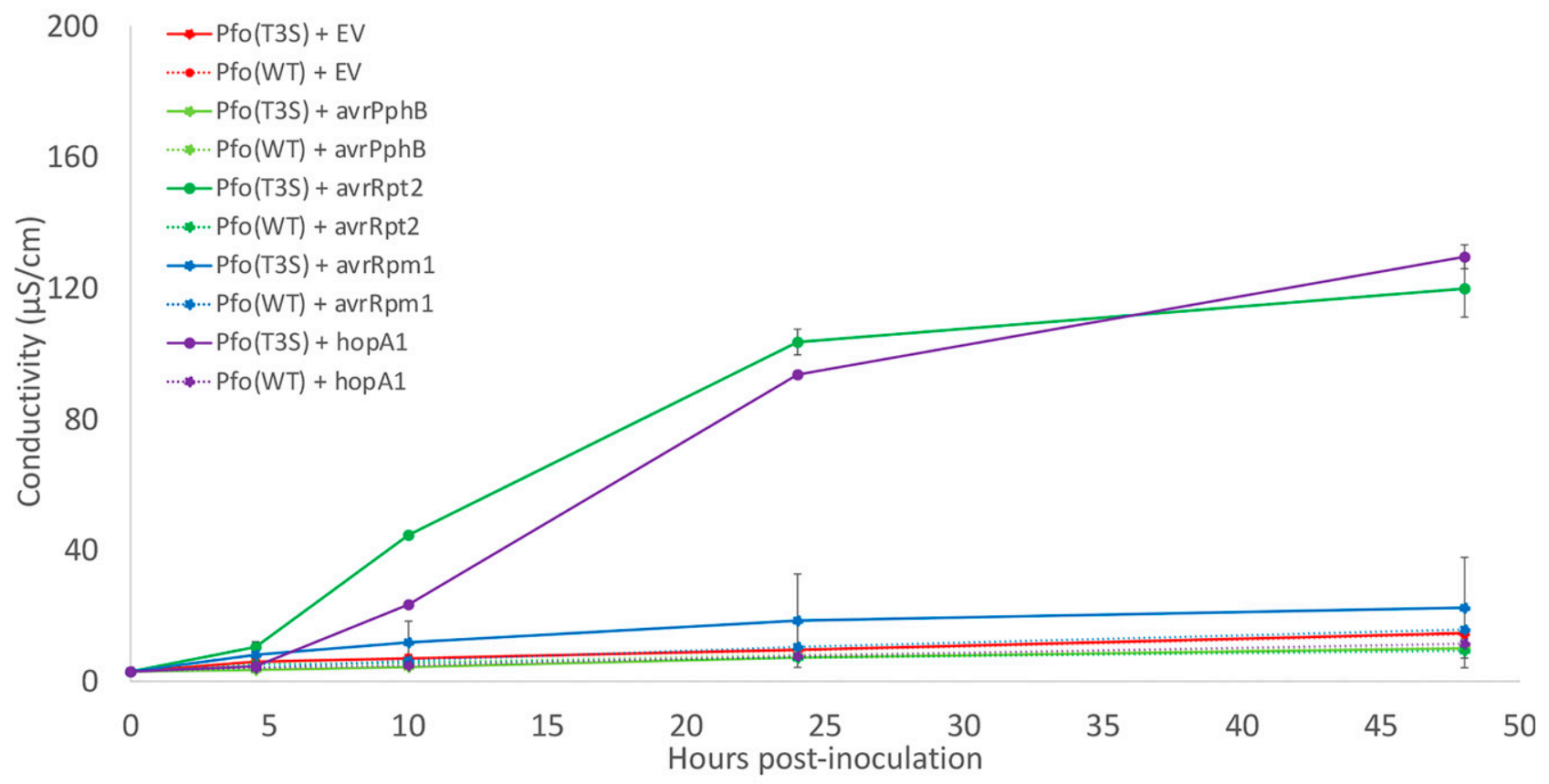

B

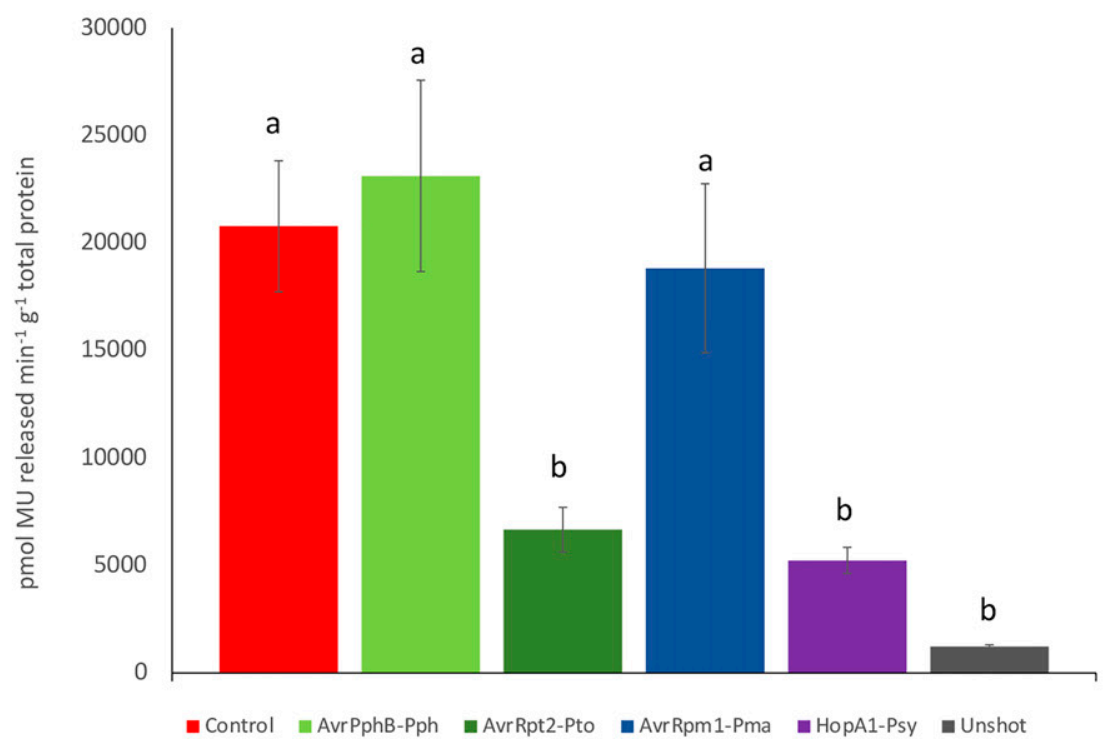

Fig. 4. Actinidia arguta AA07_03 recognizes effectors AvrRpt $2_{P t o \mathrm{~T} 1}$ and HopA1 $1_{P s y 61}$ but not AvrRpm $1_{P m a \mathrm{M} 2}$ when delivered in isolation or during transient expression. A, Measurement of hypersensitive response (HR) by electrolyte leakage. Leaf discs from AA07_03 plantlets were vacuum-infiltrated with $P$. fluorescens Pf0-1 wild type (WT) or type III secretion system carrying mutant (T3S), empty vector (EV), or putative avirulence effectors avrRpm1 ${ }_{P m a \mathrm{M} 2}$, avrRpt $2_{P t o T 1}, a v r P p h B_{P p h 1448 \mathrm{~A}}$, or hopA $1_{P s y 61}$ inoculum at approximately $10^{8} \mathrm{CFU} / \mathrm{ml}$, and electrical conductivity due to HR-associated electrolyte leakage measured at selected timepoints over $48 \mathrm{~h}$. Error bars represent the standard errors of the means calculated from five biological replicates. B, Putative avirulence effectors described in A cloned on binary vector constructs or corresponding empty vector (EV) were coexpressed with a $\beta$-glucuronidase (GUS) reporter construct, using biolistic bombardment and priming in AA07_03 plantlets. The GUS activity was measured $48 \mathrm{~h}$ after DNA bombardment. Error bars represent the standard errors of the means for three independent biological replicates with six technical replicates each $(n=18)$. Letters indicate results of a one-way analysis of variance and Tukey's honest significant difference post hoc test $(P<0.01)$, shared letters indicate no significant difference. 
HR in Hort16A (Fig. 4). It is possible that, in the case of AvrRpm1, because of its similarity to an existing Psa3 effector $\left(A v r R p m 1_{P s a 3}\right)$, members of the large effector repertoire in Psa3 are able to block HR and growth restriction (Sawada and Fujikawa 2019). Indeed, $P$ syringae pv. actinidiae strains appear to have a larger than expected repertoire of putative RIN4-targeting and HopF-related effectors, including AvrRpm1, AvrRpm2, HopF4b (a.k.a. HopF2), HopX3, HopZ3, HopBB1, and HopBN1 (McCann et al. 2017, 2013; Sawada and Fujikawa 2019). These effectors may, independently or in combination, act to suppress HR triggered by other effectors targeting the same pathways. It is therefore intriguing that AvrRpt2, another RIN4-targeting effector, is still able to trigger both HR (in isolation) and growth restriction, despite triggering a weaker HR than AvrRpm1 in Hort16A plants. Alternatively, the presence of several demonstrated HR-suppressing effectors in Psa3 may be able to counteract avirulence triggered by AvrRpm1 (Choi et al. 2017). These HR-suppressing effectors displayed avirulence effector-specific HR suppression ability. In contrast, the HR against AvrRpt2 and HopA1 are not suppressed because Psa3 does not carry orthologous effectors in its repertoire, and thus, has not evolved the ability to suppress immunity triggered by these two effectors. Nevertheless, the identification of HR and immunity suppressors against recognition of AvrRpm1 (specifically the ortholog from $P$. syringae pv. maculicola $\mathrm{M} 2$ ) may render any immunity against the ortholog of this effector from Psa3 less useful for breeding efforts, highlighting the need for multipronged approaches to discovering effectors in $P s a 3$ that trigger immunity in resistant kiwifruit. Thus, it appears that electrolyte leakage (or biolistic reporter eclipse assays or both) are useful for determining effectors that, in isolation, are able to trigger an HR, but they need to be checked with in-planta pathogen growth assays to determine if the accompanying HR results in resistance in the host plant.

The further use of a defense-associated reporter gene (WRKY70a) to assess whether phenotypes observed are authentic defense responses was also utilized (Supplementary Fig. S4). Interestingly, Psa3 $\Delta h r c C$ mutant was also able to trigger a defense response in $A$. arguta to a level similar to that by WT Psa3. This is not unexpected, since both PTI and ETI pathways appear to be convergent on immune signaling and ETI activation by WRKY70 appears to require PTI (Knoth et al. 2007; Ngou et al. 2021; Yuan et al. 2021; Zhou et al. 2018). Notably, however, while Psa3 did not trigger significant AcWRKY70 expression in Hort16A as expected, Hort16A also did not appear capable of detecting the Psa3 $\Delta h r c C$ mutant and this may partially explain the extreme susceptibility of this cultivar to Psa3 infection (Supplementary Fig. S4).

A major hurdle in breeding disease resistance is the apparently quantitative nature of one or both disease severity and resistance in segregating mapping populations. ETI is typically conferred by a single, dominant, intracellular NLR protein recognizing the action of a single avirulence effector (Dangl et al. 2013). Multiple nonredundant NLRs recognizing multiple effectors required for pathogen virulence would likely provide durable disease resistance. However, these NLRs may be difficult to map in a breeding population using the pathogen itself, as they would present as a complex quantitative phenotype, particularly with the interplay of multiple effectors and their associated virulence functions (Corwin and Kliebenstein 2017). By using cloned effectors in isolation of other effectors from the pathogen, the process of mapping corresponding resistance loci can be accelerated, as disease resistance scoring is likely to be simple and individual effector recognition is most likely conferred by a single dominant locus. Testing isolated effectors for recognition via a high-throughput platform, instead of relying on pathogen virulence, identification of one or more corresponding NLRs by mapping using this approach, and identifying NLR-associated molecular markers is the most efficacious approach to accelerate breeding new resistant cultivars. Such effector-assisted breeding approaches are currently at the forefront of nontransgenic resistance breeding programs around the world (Vleeshouwers and Oliver 2014; Zhang and Coaker 2017). Effector-assisted resistance strategies have been successfully deployed against potato late blight, rice blast, and bacterial blight in cassava (Bart et al. 2012; Ning et al. 2020; Vleeshouwers et al. 2008). Introgression of major Psa3 disease resistance loci into commercial cultivars can be facilitated in kiwifruit breeding programs using a similar approach.

The resistance offered by $A$. arguta in response to Psa3 is a promising source for future analysis and possible deployment. A. arguta has proved durably resistant and largely disease-free in the field, despite identification of some $P$ syringae pv. actinidiae in isolated sampling from $A$. arguta vines in orchards (McCann et al. 2017; Vanneste et al. 2014). Using an effector-guided strategy to discover avirulence effectors from Psa3 would allow screening of hybrid mapping populations generated from $A$. arguta crossed with commercially attractive $A$. chinensis var. chinensis or A. chinensis var. deliciosa species to select lines that could provide durable resistance to Psa3. The simplicity of an efficient, rapid, high-throughput screening approach enables this goal to be realized in a realistic and efficient manner.

\section{MATERIALS AND METHODS}

\section{Bacterial strains and plasmids.}

P. syringae pv. actinidiae ICMP 18884 biovar 3 strain (Psa3, also referred to as $P$ syringae pv. actinidiae V13 or NZ13 [McCann et al. 2013]) and P. fluorescens Pf0-1 strains (Thomas et al. 2009) were streaked from glycerol stocks onto lysogeny broth (LB) agar (Bertani 1951) supplemented with antibiotics (all from Sigma Aldrich). Psa3 was supplemented with nitrofurantoin at $12.5 \mu \mathrm{g} / \mathrm{ml}$, cephalexin at $40 \mu \mathrm{g} / \mathrm{ml}$, and either kanamycin at $50 \mu \mathrm{g} / \mathrm{ml}$ or gentamicin at $25 \mu \mathrm{g} / \mathrm{ml} ;$ P. fluorescens was supplemented with chloramphenicol at $10 \mu \mathrm{g} / \mathrm{ml}$, tetracycline (only for $\mathrm{T} 3 \mathrm{~S}$ ) at $5 \mu \mathrm{g} / \mathrm{ml}$, and either kanamycin at $50 \mu \mathrm{g} / \mathrm{ml}$ or gentamicin at $25 \mu \mathrm{g} / \mathrm{ml}$. Petri plates were sealed and grown for $48 \mathrm{~h}$ at $22^{\circ} \mathrm{C}$. Overnight shaking liquid cultures inoculated from plates were grown in LB supplemented with appropriate antibiotics and incubated at $22^{\circ} \mathrm{C}$ with shaking at $200 \mathrm{rpm}$.

pVSP61 (AvrPphB, AvrRpt2, or AvrRpm1) or pML123 (HopA1) plasmids (Bisgrove et al. 1994; Century et al. 1995; Kunkel et al. 1993; van Dijk et al. 2002) carrying avirulence effectors were transformed into Psa3 or P. fluorescens strains using rapid electrocompetent cell preparation methodologies described earlier (Choi et al. 2006; Mesarich et al. 2017) and were transformed using a BioRad Gene Pulser Xcell electroporation system (Bio$\mathrm{Rad}$ ), using the " $P$. aeruginosa" program settings, and were recovered for $1 \mathrm{~h}$ in LB before plating on selective media. Positive transformants were confirmed by gene-specific colony PCR.

\section{Plant material and in-planta growth assay.}

Actinidia spp. plantlets of $A$. chinensis var. chinensis Hort16A, A. chinensis var. chinensis Zesy002 (also called Gold3), A. chinensis var. deliciosa Hayward, or A. arguta AA07_03 were obtained from Multiflora Laboratories. Plantlets were grown from shooted callus tissues in $400 \mathrm{ml}$-lidded plastic 'pottles' on half-strength Murashige and Skoog (MS) agar, with three to five plantlets per pottle. Plantlets were grown in a climate-controlled room at $20^{\circ} \mathrm{C}$ with a 16-h-light and 8-h-dark cycle and were used when they were 2 to 4 months old.

Psa3 pathogenicity was assessed using an in-planta flooding assay, as established by McAtee et al. (2018). Briefly, overnight-grown Psa3 shaking liquid cultures were centrifuged at $5,000 \times g$ for $3 \mathrm{~min}$, supernatant was decanted, and pellets were resuspended and diluted in $10 \mathrm{mM} \mathrm{MgSO}_{4}$ to $10^{6} \mathrm{CFU} / \mathrm{ml}$ (optical density at $600 \mathrm{~nm}\left[\mathrm{OD}_{600}\right]$ adjusted to 0.004 ) with Silwet 
L-77 (Lehle Seeds) (0.0025\% vol/vol). Kiwifruit plantlets were inoculated by flooding with the Psa3 cell suspension for $3 \mathrm{~min}$, fully submerging the plantlets. The inoculum was poured off the plantlets, and the pottles were resealed with lids and were kept under plant growth conditions until sampled.

In planta bacterial growth was assessed as previously described (Jayaraman et al. 2020). Briefly, four leaf discs per pseudobiological replicate (with four replicates per treatment, per timepoint), randomly sampled using a 1-cm diameter cork-borer from three plants in a single pottle, were harvested at $2 \mathrm{~h}$ (day 0 ), day 6 , and day 12 postinoculation. Each treatment timepoint was sampled from an independent pottle. Leaf discs were surface-sterilized, were placed in Eppendorf tubes containing three sterile stainlesssteel ball bearings and $350 \mu \mathrm{l}$ of $10 \mathrm{mM} \mathrm{MgSO}_{4}$, and were macerated in a Storm 24 Bullet Blender (Next Advance) for two bursts of 1 min each at maximum speed. A 10-fold dilution series of the leaf homogenates was made in sterile $10 \mathrm{mM} \mathrm{MgSO}_{4}$, until a dilution of $10^{-8}$, and was plated as $10-\mu l$ droplets on LB medium amended with antibiotics. Petri plates were sealed with Parafilm (Sigma Aldrich) and were incubated for 2 days at $20^{\circ} \mathrm{C}$ before the leaf area (colony-forming units per square centimeter) was ascertained from dilutions. Three completely independent experimental runs were conducted for each in-planta growth assay, with treatment and sampling order for each strain randomized for every run and a representative run selected for depiction. Statistical analysis was done by Student's $t$ test between control (wild-type Psa3) and variants. To observe pathogenic symptoms on the plants, infected pottles were kept for 50 dpi and photographs were taken of pottles. Infection severity was qualitatively assessed based on typical symptoms, i.e., necrotic leaf spots, chlorotic haloes, leaf death, and plant death. Each symptomology assessment was conducted on independent batches of plants (one pottle per treatment) at least three times, with treatment and sampling order for each strain randomized for every run.

\section{DNA extraction and qPCR.}

The PDQeX extraction platform (MicroGEM) was used to perform single-step DNA extraction in under $30 \mathrm{~min}$ (Stanton et al. 2019). Genomic DNA was extracted from infected leaf homogenate samples (as prepared for in-planta growth assays prior to serial dilution) at $7 \mathrm{dpi}$. Leaf homogenate $(20 \mu \mathrm{l})$ was added to $80 \mu \mathrm{l}$ of the master mix containing GREEN+ buffer, reaction enhancer, PrepGEM, and Histosolv (according to kit specifications) in a phytoGEM extraction tube, and extraction run under a modified 'Plant' program on a PDQeX nucleic acid extractor (MicroGEM). The 'Plant' program protocol used was $52^{\circ} \mathrm{C}$ for $10 \mathrm{~min}, 75^{\circ} \mathrm{C}$ for $10 \mathrm{~min}, 95^{\circ} \mathrm{C}$ for $2 \mathrm{~min}$, then cooling to $30^{\circ} \mathrm{C}$.

Real-time qPCR was carried out on an Illumina Eco real-time PCR platform, using SsoFast EvaGreen Supermix (BioRad) with $2 \mu \mathrm{l}$ of PDQeX template DNA. qPCR was performed over 40 cycles using $P$ syringae pv. actinidiae intergenic transcribed spacer (ITS) (target) and AcEF $1 \alpha$ (reference) primers and protocol outlined by Barrett-Manako et al. (2021) but with a lower melting temperature of $57^{\circ} \mathrm{C}$. qPCR results were reported as relative expression $\log _{10}$ values of $2^{(\mathrm{CtPs} a \mathrm{ITS}-\mathrm{Ct} A c E F 1 \alpha)}$ for each sample with means and standard errors calculated for four pseudobiological replicates. This infection-sampling PDQeX-qPCR experiment was conducted three times on independent batches of plants. Samples were statistically analyzed for significance by analysis of variance (ANOVA) followed by a Tukey's honest significant difference (HSD) post hoc test.

\section{Vacuum infiltration and electrolyte leakage assay.}

$P$. fluorescens (T3S or WT) carrying empty vector or effector constructs were streaked from glycerol stocks onto LB agar plates with antibiotic selection, were grown for 2 days at $22^{\circ} \mathrm{C}$, and were restreaked on fresh agar media, and were allowed to grow overnight. Bacteria were then harvested from plates, were resuspended in $10 \mathrm{mM} \mathrm{MgCl}_{2}$, and were diluted to required $\mathrm{OD}_{600}=$ 1 (approximately $10^{8} \mathrm{CFU} / \mathrm{ml}$ ). Vacuum-infiltrations were carried out using a pump and glass bell. Leaves were harvested from the tissue culture tubs and were submerged in $30 \mathrm{ml}$ of bacterial inoculum. The vacuum was run until bubbles were rapidly forming. The vacuum valve was then shut and the air slowly let back in. The infiltration was repeated a second time for those leaves not fully infiltrated and any remaining non-infiltrated leaves were removed, as determined by visual examination. For each treatment, leaf discs (6 $\mathrm{mm}$ diameter) were harvested from the uniformly vacuum-infiltrated leaf area and were washed in distilled water for $1 \mathrm{~h}$. Six discs were placed in $3 \mathrm{ml}$ of water, and conductivity was measured over $48 \mathrm{~h}$, using a LAQUAtwin EC-33 conductivity meter (Horiba). The standard errors of the means were calculated from five pseudobiological replicates. Data for each timepoint was analyzed by ANOVA followed by a Tukey's HSD post hoc test. The entire experiment was conducted three times on independent batches of plants.

\section{Constitutive-expression binary vector cloning.}

Each effector sequence was PCR-amplified (primers in Supplementary Table S1) as a single module with flanking BsaI site-containing primers, using Platinum Taq HiFi polymerase (Thermo Fischer). Amplified PCR products were ligated with Eco53kI-digested (avrPphB, avrRpml, and hopAl) or SmaIdigested (avrRpt2) entry vector pICH41021. Ligated constructs were verified by Sanger sequencing. The $s h c A$ chaperone for hopAl was not included in the module amplified. Each of the effector modules was assembled into the constitutive-expression binary vector pICH86988 (under the cauliflower mosaic virus $35 \mathrm{~S}$ promoter and tobacco mosaic virus $\Omega$ leader) with either a C-terminal yellow fluorescent protein $(\operatorname{avrPph}$ and hopAl) or $3 x$ FLAG tag (avrRpml and avrRpt2), using the Golden Gate assembly method (Engler et al. 2008).

\section{Biolistic co-bombardment reporter eclipse assay.}

Fresh young leaves of $A$. chinensis Hort16A or A. arguta AA07_03 [10 mm (W) $\times 20 \mathrm{~mm}(\mathrm{~L})]$ were excised from 4-week-old in vitro-grown plantlets. Two hours prior to bombardment, three leaves were placed in the center of a circular $15-\mathrm{mm}$ Whatman No. 2 filter paper disc on solidified MS medium Petri plates before bombardment. Plasmid DNA was prepared using Qiagen plasmid midi kits (Qiagen) according to manufacturer instructions.

Particle bombardment was carried out using the particle inflow gun made by KiwiScientific (Whangarei), based on the design by Finer et al. (1992). DNA-coated gold particles $(1.0 \mu \mathrm{m}$ diameter [Bio-Rad]) were prepared as follows. A 50- $\mu$ l aliquot of gold suspension containing $5 \mathrm{mg}$ of gold particles in distilled water was mixed with $10 \mu \mathrm{g}$ of GUS plasmid pRT99-GUS (Töpfer et al. 1988) and $10 \mu \mathrm{g}$ of pICH86988 empty vector (Weber et al. 2011) or vector containing the cloned effector of interest, $20 \mu \mathrm{l}$ of $100 \mathrm{mM}$ spermidine, and $50 \mu \mathrm{l}$ of $2.5 \mathrm{M} \mathrm{CaCl}_{2}$. The solution was vortexed vigorously for $2 \mathrm{~min}$ and was incubated at room temperature for $10 \mathrm{~min}$. The supernatant was carefully removed to leave a $35-\mu 1$ final volume for bombardment.

For each bombardment, $5 \mu \mathrm{l}$ of a well-mixed particle preparation was loaded onto a syringe filter carrier and the bombardment was performed using the following conditions: shot distance $=14$ $\mathrm{cm}$ from the carrier to the target shelf, helium pressure $=300 \mathrm{KPa}$, pulse time $=30 \mathrm{~ms}$, chamber vacuum $=-90 \mathrm{KPa}$. Target leaves were held (abaxial side uppermost) under a stainless-steel mesh $(100 \mu \mathrm{m})$ and were bombarded once. Six bombardments were performed for each particle preparation, and each experiment was carried out in triplicate. After bombardment, the leaves were immersed in a 20-ml suspension of Agrobacterium tumefaciens 
GV3101 ( $\mathrm{OD}_{600}$ adjusted to 0.6$)$ for $30 \mathrm{~s}$, after which they were transferred onto solid MS medium.

After $48 \mathrm{~h}$ of incubation in the light at room temperature, the leaf tissue was frozen in liquid nitrogen and was ground at $4 \mathrm{~m} / \mathrm{s}$ for $20 \mathrm{~s}$ with metal beads, using a Bead Ruptor Elite (Omni International, Inc.). The frozen tissue powder (approximately300 mg) was then mixed by vigorous vortexing with $1 \mathrm{ml}$ of GUS extraction buffer (50 mM sodium phosphate buffer [pH 7.0], $10 \mathrm{mM}$ EDTA, $0.1 \%$ Triton X-100 [vol/voll, $0.1 \%$ N-lauryl sarcosine [wt/vol], $10 \mathrm{mM} \beta$-mercaptoethanol, $1 \%$ of polyvinylpolypyrrolidone [wt/vol], 20\% methanol [vol/vol], and one Complete ULTRA Mini Protease inhibitor cocktail tablet for every $10 \mathrm{ml}$ of extraction buffer (all from Sigma Aldrich). The crude extract was centrifuged at $18,000 \times g$ for $15 \mathrm{~min}$ at $4^{\circ} \mathrm{C}$, and the supernatant was collected and assayed. The protein concentration was determined using the Bio-Rad protein assay kit (Bio-Rad Laboratories), following manufacturer instructions. The GUS activity was determined using $100 \mu \mathrm{l}$ of leaf extract with methylumbelliferyl- $\beta$-glucuronide as the substrate, following the method described by Hunter and Watson (2008). The amount of 4-methylumbelliferyl (MU) product was measured in a Tecan Safire2 fluorescence microplate reader (Tecan). For each bombardment, triplicate samples (technical replicates) were assayed and expressed in terms of pmol of MU produced per minute per gram of total protein. The means and standard errors were calculated from 18 replicates conducted across three independent experimental runs. Data for each treatment was stacked from all three runs and was analyzed by ANOVA followed by a Tukey's HSD post hoc test.

\section{ACKNOWLEDGMENTS}

We would like to thank J. Rees (The New Zealand Institute for Plant and Food Research Limited (PFR), Ruakura Research Centre, New Zealand) for glasshouse plant work. We would also like to thank J. Bowen (PFR) and E. Rikkerink (PFR) for critically reading the manuscript.

\section{LITERATURE CITED}

Abdullah, A. S., Turo, C., Moffat, C. S., Lopez-Ruiz, F. J., Gibberd, M. R., Hamblin, J., and Zerihun, A. 2018. Real-time PCR for diagnosing and quantifying co-infection by two globally distributed fungal pathogens of wheat. Front. Plant Sci. 9:1086.

Agrawal, P. K., Kohli, A., Twyman, R. M., and Christou, P. 2005. Transformation of plants with multiple cassettes generates simple transgene integration patterns and high expression levels. Mol. Breed. 16:247-260.

Barrett-Manako, K., Andersen, M. T., Martínez-Sánchez, M., Jenkins, H., Hunter, S., Rees-George, J., Montefiori, M., Wohlers, M., Rikkerink, E., Templeton, M., and Nardozza, S. 2021. Real-time PCR and droplet digital PCR are accurate and reliable methods to quantify Pseudomonas syringae pv. actinidiae biovar 3 in kiwifruit infected plantlets. Plant Dis. Published online. https://doi.org/10.1094/PDIS-08-20-1703-RE

Bart, R., Cohn, M., Kassen, A., McCallum, E. J., Shybut, M., Petriello, A., Krasileva, K., Dahlbeck, D., Medina, C., Alicai, T., Kumar, L., Moreira, L. M., Rodrigues Neto, J., Verdier, V., Santana, M. A., Kositcharoenkul, N., Vanderschuren, H., Gruissem, W., Bernal, A., and Staskawicz, B. J. 2012. High-throughput genomic sequencing of cassava bacterial blight strains identifies conserved effectors to target for durable resistance. Proc. Natl. Acad. Sci. U.S.A. 109:E1972-E1979.

Bertani, G. 1951. Studies on lysogenesis. I. The mode of phage liberation by lysogenic Escherichia coli. J. Bacteriol. 62:293-300.

Bisgrove, S. R., Simonich, M. T., Smith, N. M., Sattler, A., and Innes, R. W. 1994. A disease resistance gene in Arabidopsis with specificity for two different pathogen avirulence genes. Plant Cell 6:927-933.

Brendolise, C., Martinez-Sanchez, M., Morel, A., Chen, R., Dinis, R., Deroles, S., Peeters, N., Rikkerink, E. H. A., and Montefiori, M. 2018. NRG1-mediated recognition of HopQ1 reveals a link between PAMPand effector-triggered immunity. BioRxiv. https://doi.org/10.1101/293050

Brendolise, C., Montefiori, M., Dinis, R., Peeters, N., Storey, R. D., and Rikkerink, E. H. 2017. A novel hairpin library-based approach to identify NBS-LRR genes required for effector-triggered hypersensitive response in Nicotiana benthamiana. Plant Methods 13:32.
Brouwer, M., Lievens, B., Van Hemelrijck, W., Van den Ackerveken, G., Cammue, B. P. A., and Thomma, B. P. H. J. 2003. Quantification of disease progression of several microbial pathogens on Arabidopsis thaliana using real-time fluorescence PCR. FEMS Microbiol. Lett. 228:241-248.

Century, K. S., Holub, E. B., and Staskawicz, B. J. 1995. NDR1, a locus of Arabidopsis thaliana that is required for disease resistance to both a bacterial and a fungal pathogen. Proc. Natl. Acad. Sci. U.S.A. 92:65976601.

Choi, K.-H., Kumar, A., and Schweizer, H. P. 2006. A 10-min method for preparation of highly electrocompetent Pseudomonas aeruginosa cells: Application for DNA fragment transfer between chromosomes and plasmid transformation. J. Microbiol. Methods 64:391-397.

Choi, S., Jayaraman, J., Segonzac, C., Park, H.-J., Park, H., Han, S.-W., and Sohn, K. H. 2017. Pseudomonas syringae pv. actinidiae type III effectors localized at multiple cellular compartments activate or suppress innate immune responses in Nicotiana benthamiana. Front. Plant Sci. $8: 2157$.

Clarke, C. R., Cai, R., Studholme, D. J., Guttman, D. S., and Vinatzer, B. A. 2010. Pseudomonas syringae strains naturally lacking the classical $P$. syringae hrp/hrc Locus are common leaf colonizers equipped with an atypical type III secretion system. Mol. Plant-Microbe Interact. 23: 198-210.

Clarke, C. R., Hayes, B. W., Runde, B. J., Wicker, E., and Vinatzer, B. A 2014. Eggplant and related species are promising genetic resources to dissect the plant immune response to Pseudomonas syringae and Xanthomonas euvesicatoria and to identify new resistance determinants. Mol. Plant Pathol. 15:814-822.

Cook, D. E., Mesarich, C. H., and Thomma, B. P. H. J. 2015. Understanding plant immunity as a surveillance system to detect invasion. Annu. Rev. Phytopathol. 53:541-563.

Corwin, J. A., and Kliebenstein, D. J. 2017. Quantitative resistance: More than just perception of a pathogen. Plant Cell 29:655-665.

Dangl, J. L., Horvath, D. M., and Staskawicz, B. J. 2013. Pivoting the plant immune system from dissection to deployment. Science 341:746-751.

Donati, I., Cellini, A., Sangiorgio, D., Vanneste, J. L., Scortichini, M., Balestra, G. M., and Spinelli, F. 2020. Pseudomonas syringae pv. actinidiae: Ecology, infection dynamics and disease epidemiology. Microb. Ecol. 80:81-102.

Du, J., Rietman, H., and Vleeshouwers, V. G. A. A. 2014. Agroinfiltration and PVX agroinfection in potato and Nicotiana benthamiana. J. Vis Exp. 83:e50971.

Engler, C., Kandzia, R., and Marillonnet, S. 2008. A one pot, one step, precision cloning method with high throughput capability. PLoS One 3: e3647.

Fan, J., Crooks, C., and Lamb, C. 2008. High-throughput quantitative luminescence assay of the growth in planta of Pseudomonas syringae chromosomally tagged with Photorhabdus luminescens luxCDABE. Plant J. 53:393-399.

Finer, J. J., Vain, P., Jones, M. W., and McMullen, M. D. 1992. Development of the particle inflow gun for DNA delivery to plant cells. Plant Cell Rep. 11:323-328.

Gallelli, A., Talocci, S., Pilotti, M., and Loreti, S. 2014. Real-time and qualitative PCR for detecting Pseudomonas syringae pv. actinidiae isolates causing recent outbreaks of kiwifruit bacterial canker. Plant Pathol. 63:264-276.

Gassmann, W. 2005. Natural variation in the Arabidopsis response to the avirulence gene hopPsyA uncouples the hypersensitive response from disease resistance. Mol. Plant-Microbe Interact. 18:1054-1060.

Gopalan, S., Bauer, D. W., Alfano, J. R., Loniello, A. O., He, S. Y., and Collmer, A. 1996. Expression of the Pseudomonas syringae avirulence protein AvrB in plant cells alleviates its dependence on the hypersensitive response and pathogenicity (Hrp) secretion system in eliciting genotypespecific hypersensitive cell death. Plant Cell 8:1095-1105.

Guo, M., Tian, F., Wamboldt, Y., and Alfano, J. R. 2009. The majority of the type III effector inventory of Pseudomonas syringae pv. tomato DC3000 can suppress plant immunity. Mol. Plant-Microbe Interact. 22:1069-1080.

Hayta, S., Smedley, M. A., Demir, S. U., Blundell, R., Hinchliffe, A., Atkinson, N., and Harwood, W. A. 2019. An efficient and reproducible Agrobacterium-mediated transformation method for hexaploid wheat (Triticum aestivum L.). Plant Methods 15:121.

Hoyte, S., Reglinski, T., Elmer, P., Mauchline, N., Stannard, K., Casonato, S., Ah Chee, A., Parry, F., Taylor, J., Wurms, K., Yu, J., Cornish, D., and Parry, J. 2015. Developing and using bioassays to screen for Psa resistance in New Zealand kiwifruit. Acta Hortic.: 171-180.

Hunter, D. A., and Watson, L. M. 2008. The harvest-responsive region of the Asparagus officinalis sparagine synthetase promoter reveals 
complexity in the regulation of the harvest response. Funct. Plant Biol. 35:1212-1223.

Jayaraman, J., Choi, S., Prokchorchik, M., Choi, D. S., Spiandore, A., Rikkerink, E. H., Templeton, M. D., Segonzac, C., and Sohn, K. H. 2017. A bacterial acetyltransferase triggers immunity in Arabidopsis thaliana independent of hypersensitive response. Sci. Rep. 7:3557.

Jayaraman, J., Yoon, M., Applegate, E. R., Stroud, E. A., and Templeton, M. D. 2020. AvrE1 and HopR1 from Pseudomonas syringae pv. actinidiae are additively required for full virulence on kiwifruit (preprint). Pathology 21:1467-1480.

Jelly, N. S., Valat, L., Walter, B., and Maillot, P. 2014. Transient expression assays in grapevine: A step towards genetic improvement. Plant Biotechnol. J. 12:1231-1245.

Jia, Y., McAdams, S. A., Bryan, G. T., Hershey, H. P., and Valent, B. 2000. Direct interaction of resistance gene and avirulence gene products confers rice blast resistance. EMBO J. 19:4004-4014.

Jones, J. D. G., Vance, R. E., and Dangl, J. L. 2016. Intracellular innate immune surveillance devices in plants and animals. Science 354: aaf6395.

Knoth, C., Ringler, J., Dangl, J. L., and Eulgem, T. 2007. Arabidopsis WRKY70 is required for full RPP4-mediated disease resistance and basal defense against Hyaloperonospora parasitica. Mol. PlantMicrobe Interact. 20:120-128.

Kunkel, B. N., Bent, A. F., Dahlbeck, D., Innes, R. W., and Staskawicz, B. J. 1993. RPS2, an Arabidopsis disease resistance locus specifying recognition of Pseudomonas syringae strains expressing the avirulence gene avrRpt2. Plant Cell 5:865-875.

Lacroix, B., and Citovsky, V. 2020. Biolistic approach for transient gene expression studies in plants. Pages 125-139 in: Biolistic DNA Delivery in Plants, Methods in Molecular Biology. Rustgi, S., and Luo, H., eds. Springer US, New York, NY.,

Laflamme, B., Dillon, M. M., Martel, A., Almeida, R. N. D., Desveaux, D., and Guttman, D. S. 2020. The pan-genome effector-triggered immunity landscape of a host-pathogen interaction. Science 367:763-768.

McAtee, P. A., Brian, L., Curran, B., van der Linden, O., Nieuwenhuizen, N. J., Chen, X., Henry-Kirk, R. A., Stroud, E. A., Nardozza, S., Jayaraman, J., Rikkerink, E. H. A., Print, C. G., Allan, A. C., and Templeton, M. D. 2018. Re-programming of Pseudomonas syringae pv. actinidiae gene expression during early stages of infection of kiwifruit. BMC Genomics 19:822.

McCann, H. C., Li, L., Liu, Y., Li, D., Pan, H., Zhong, C., Rikkerink, E. H. A., Templeton, M. D., Straub, C., Colombi, E., Rainey, P. B., and Huang, H. 2017. Origin and evolution of the kiwifruit canker pandemic. Genome Biol. Evol. 9:932-944.

McCann, H. C., Rikkerink, E. H. A., Bertels, F., Fiers, M., Lu, A., ReesGeorge, J., Andersen, M. T., Gleave, A. P., Haubold, B., Wohlers, M. W., Guttman, D. S., Wang, P. W., Straub, C., Vanneste, J. L., Rainey, P. B., and Templeton, M. D. 2013. Genomic analysis of the kiwifruit pathogen Pseudomonas syringae pv. actinidiae provides insight into the origins of an emergent plant disease. PLoS Pathog. 9:e1003503.

Mesarich, C. H., Rees-George, J., Gardner, P. P., Ghomi, F. A., Gerth, M. L., Andersen, M. T., Rikkerink, E. H. A., Fineran, P. C., and Templeton, M. D. 2017. Transposon insertion libraries for the characterization of mutants from the kiwifruit pathogen Pseudomonas syringae pv. actinidiae. PLoS One 12:e0172790.

Mindrinos, M., Katagiri, F., Yu, G.-L., and Ausubel, F. M. 1994. The A. thaliana disease resistance gene RPS2 encodes a protein containing a nucleotide-binding site and leucine-rich repeats. Cell 78:1089-1099.

Nardozza, S., Martinez-Sanchez, M., Curtis, C., Datson, P. M., and Montefiori, M. 2015. Screening Actinidia germplasm for different levels of tolerance, or resistance, to Psa (Pseudomonas syringae pv. actinidiae). Acta Hortic.: 351-355.

Narusaka, M., Shirasu, K., Noutoshi, Y., Kubo, Y., Shiraishi, T., Iwabuchi, M., and Narusaka, Y. 2009. RRS1 and RPS4 provide a dual Resistancegene system against fungal and bacterial pathogens. Plant J. 60:218-226.

Ngou, B. P. M., Ahn, H.-K., Ding, P., and Jones, J. D. G. 2021. Mutual potentiation of plant immunity by cell-surface and intracellular receptors. Nature 592:110-115.

Ning, X., Yunyu, W., and Aihong, L. 2020. Strategy for use of rice blast resistance genes in rice molecular breeding. Rice Sci. 27:263-277.

Rietman, H., Bijsterbosch, G., Cano, L. M., Lee, H.-R., Vossen, J. H., Jacobsen, E., Visser, R. G. F., Kamoun, S., and Vleeshouwers, V. G. A. A. 2012. Qualitative and quantitative late blight resistance in the potato cultivar Sarpo Mira is determined by the perception of five distinct RXLR effectors. Mol. Plant-Microbe Interact. 25:910-919.
Ross, A., and Somssich, I. E. 2016. A DNA-based real-time PCR assay for robust growth quantification of the bacterial pathogen Pseudomonas syringae on Arabidopsis thaliana. Plant Methods 12:48.

Sawada, H., and Fujikawa, T. 2019. Genetic diversity of Pseudomonas syringae pv. actinidiae, pathogen of kiwifruit bacterial canker. Plant Pathol. 68:1235-1248.

Stanton, J. L., Muralidhar, A., Rand, C. J., and Saul, D. J. 2019. Rapid extraction of DNA suitable for NGS workflows from bacterial cultures using the PDQeX. Biotechniques 66:208-213.

Tahir, J., Hoyte, S., Bassett, H., Brendolise, C., Chatterjee, A., Templeton, K., Deng, C., Crowhurst, R., Montefiori, M., Morgan, E., Wotton, A., Funnell, K., Wiedow, C., Knaebel, M., Hedderley, D., Vanneste, J., McCallum, J., Hoeata, K., Nath, A., Chagné, D., Gea, L., and Gardiner, S. E. 2019. Multiple quantitative trait loci contribute to resistance to bacterial canker incited by Pseudomonas syringae pv. actinidiae in kiwifruit (Actinidia chinensis). Hortic. Res. 6:101.

Thomas, W. J., Thireault, C. A., Kimbrel, J. A., and Chang, J. H. 2009. Recombineering and stable integration of the Pseudomonas syringae pv. syringae $61 \mathrm{hrp} / \mathrm{hrc}$ cluster into the genome of the soil bacterium Pseudomonas fluorescens Pf0-1. Plant J. 60:919-928.

Töpfer, R., Schell, J., and Steinbiss, H.-H. 1988. Versatile cloning vectors for transient gene expression and direct gene transfer in plant cells. Nucleic Acids Res. 16:8725.

Ueki, S., Magori, S., Lacroix, B., and Citovsky, V. 2013. Transient gene expression in epidermal cells of plant leaves by biolistic DNA delivery. Pages 17-26 in: Biolistic DNA Delivery. Sudowe, S., and Reske-Kunz, A. B., eds. Humana Press, Totowa, NJ, U.S.A.

van Dijk, K., Tam, V. C., Records, A. R., Petnicki-Ocwieja, T., and Alfano, J. R. 2002. The ShcA protein is a molecular chaperone that assists in the secretion of the HopPsyA effector from the type III (Hrp) protein secretion system of Pseudomonas syringae. Mol. Microbiol. 44:1469-1481.

Vanneste, J. L., Cornish, D. A., Yu, J., and Stokes, C. A. 2014. First report of Pseudomonas syringae pv. actinidiae the causal agent of bacterial canker of kiwifruit on Actinidia arguta vines in New Zealand. Plant Dis. 98:418.

Vleeshouwers, V. G. A. A., and Oliver, R. P. 2014. Effectors as tools in disease resistance breeding against biotrophic, hemibiotrophic, and necrotrophic plant pathogens. Mol. Plant-Microbe Interact. 27:196-206.

Vleeshouwers, V. G. A. A., Rietman, H., Krenek, P., Champouret, N., Young, C., Oh, S.-K., Wang, M., Bouwmeester, K., Vosman, B., Visser, R. G. F., Jacobsen, E., Govers, F., Kamoun, S., and Van der Vossen, E. A. G. 2008. Effector genomics accelerates discovery and functional profiling of potato disease resistance and phytophthora infestans avirulence genes. PLoS One 3:e2875.

Wang, F., Li, J., Ye, K., Liu, P., Gong, H., Jiang, Q., Qi, B., and Mo, Q. 2019. An in vitro Actinidia bioassay to evaluate the resistance to Pseudomonas syringae pv. actinidiae. Plant Pathol. J. 35:372-380.

Weber, E., Engler, C., Gruetzner, R., Werner, S., and Marillonnet, S. 2011. A modular cloning system for standardized assembly of multigene constructs. PLoS One 6:e16765.

Weßling, R., and Panstruga, R. 2012. Rapid quantification of plantpowdery mildew interactions by $\mathrm{qPCR}$ and conidiospore counts. Plant Methods 8:35.

Whalen, M. C., Innes, R. W., Bent, A. F., and Staskawicz, B. J. 1991. Identification of Pseudomonas syringae pathogens of Arabidopsis and a bacterial locus determining avirulence on both Arabidopsis and soybean. Plant Cell 3:49-59.

Wroblewski, T., Tomczak, A., and Michelmore, R. 2005. Optimization of Agrobacterium-mediated transient assays of gene expression in lettuce, tomato and Arabidopsis. Plant Biotechnol. J. 3:259-273.

Yuan, M., Jiang, Z., Bi, G., Nomura, K., Liu, M., Wang, Y., Cai, B., Zhou, J.-M., He, S. Y., and Xin, X.-F. 2021. Pattern-recognition receptors are required for NLR-mediated plant immunity. Nature 592:105-109.

Zhang, M., and Coaker, G. 2017. Harnessing effector-triggered immunity for durable disease resistance. Phytopathology 107:912-919.

Zhao, Y., Mao, W., Chen, Y., Wang, W., Dai, Z., Dou, Z., Zhang, K., Wei, L., Li, T., Zeng, B., Liu, T., Fan, Y., Yan, J., Li, B., and Jia, W. 2019. Optimization and standardization of transient expression assays for gene functional analyses in strawberry fruits. Hortic. Res. 6:53.

Zhou, M., Lu, Y., Bethke, G., Harrison, B. T., Hatsugai, N., Katagiri, F., and Glazebrook, J. 2018. WRKY70 prevents axenic activation of plant immunity by direct repression of SARD1. New Phytol. 217:700-712.

Zurbriggen, M. D., Carrillo, N., and Hajirezaei, M.-R. 2010. ROS signaling in the hypersensitive response: When, where and what for? Plant Signal. Behav. 5:393-396. 